\section{Postproduction Leaching Affects the Growing Medium and Respiration of Subirrigated Poinsettias}

\author{
Marc van Iersel ${ }^{1}$ \\ Department of Horticulture, Georgia Station, The University of Georgia, 1109 \\ Experiment Street, Griffin, GA 30223-1797
}

Additional index words. Euphorbia pulcherrima, electrical conductivity, photosynthesis, salt stress

\begin{abstract}
Poinsettias (Euphorbia pulcherrima Willd. ex Klotzsch) were grown in pots filled with $1.5 \mathrm{~L}$ of soilless growing medium and subirrigated daily with a fertilizer solution containing $\mathrm{N}$ at $210 \mathrm{mg} \cdot \mathrm{L}^{-1}$ [electrical conductivity $(\mathrm{EC})=1.5 \mathrm{dS} \cdot \mathrm{m}^{-1}$ ] for 128 days. After production, plants were placed in a whole-plant photosynthesis system and the effects of applying different volumes of water $(0,0.75,1.5$, and $3 \mathrm{~L})$ to the top of the pots were quantified. Leaching with $0.75,1.5$, or $3 \mathrm{~L}$ of water reduced the $\mathrm{EC}$ in the top and middle layers of the growing medium. Applications of $0.75 \mathrm{or} 1.5 \mathrm{~L}$ of water significantly increased the EC in the bottom third of the pots, where most of the root growth occurred. However, even in these treatments the EC in the bottom layer was only $2.6 \mathrm{dS} \cdot \mathrm{m}^{-1}$ (saturated medium extraction method), which is well within the recommended range. The $0.75-$ and $1.5-\mathrm{L}$ treatments also reduced the respiration rate of the plants by $20 \%$, but none of the treatments had a significant effect on the photosynthesis of the plants. Regression analysis indicated a negative correlation between the $\mathrm{EC}$ of the bottom layer of the growing medium and dark respiration, while the EC of the top and middle layer had no significant effect on respiration. Although top watering can increase the $\mathrm{EC}$ in the bottom layer of the growing medium, this effect is unlikely to be large enough to cause significant plant stress and damage.
\end{abstract}

Ebb and flow irrigation is a viable method to produce poinsettias without runoff (Argo and Biernbaum, 1995; Dole et al., 1994; Morvant et al., 1998). However, excessive accumulation of salts in subirrigated pots may reduce the postproduction longevity of the plants. Ebb and flow-irrigated plants dropped more of their leaves than top-watered plants in the first 3 weeks after production (Deneke et al., 1993). The electrical conductivity (EC) in the top layer of the growing medium of subirrigated poinsettias is up to 10 times as high as that in the middle and bottom layers (Argo and Biernbaum, 1995).

Kent and Reed (1996) found that the EC in the top layer of the growing medium of subirrigated pots with New Guinea impatiens (Impatiens hawkerii Bull.) or peace lily (Spathiphyllum Schott) was 2 to 5 times as high as in the middle or bottom layer. The EC of the top layer was especially high if the $\mathrm{N}$ concentration in the fertilizer was higher than optimal. Kent and Reed (1996) also reported that most of the root growth occurred in the middle and bottom layers of the growing medium; therefore a high EC in the top layer of the pot may not be important during the pro-

Received for publication 14 May 1999. Accepted for publication 22 July 1999. I thank Larry Freeman and Kevin Calhoun for their technical assistance. The cost of publishing this paper was defrayed in part by the payment of page charges. Under postal regulations, this paper therefore must be hereby marked advertisement solely to indicate this fact. 1E-mail: mvanier@gaes.griffin.peachnet.edu duction of subirrigated plants. Salt accumulation in the top layer of the growing medium occurs because evaporation from the medium surface causes an upward movement of water and fertilizer through the pot. As the water evaporates from the surface, fertilizer salts are left behind (Argo and Biernbaum, 1994, 1995).

Although salt accumulation in the top layer of the growing medium also occurs in topwatered plants, it is much more pronounced in subirrigated plants (Argo and Biernbaum, 1995). When plants with high salt accumulation in the upper portion of the growing medium are top-watered in the postproduction environment, the salts can be washed down into the bottom layer of the pot, where most of the root growth occurs. This could result in salt stress, which may explain the increase in postproduction leaf drop of subirrigated poinsettias, as compared to top-watered plants (Deneke et al., 1993). Salt accumulation in the root zone can affect the metabolism of plants because of osmotic stress, specific ion toxicities, or ionic imbalance (Dubey, 1996). Salt stress can reduce photosynthesis through both stomatal and nonstomatal effects, but these responses are species-specific (Heuer, 1996). The $\mathrm{CO}_{2}$ exchange rate of plants is very sensitive to salt stress (Reddy et al., 1997) and may therefore be a good indicator of possible detrimental effects of leaching on the plants.

Accumulated salts can be removed by topwatering the medium at the end of the production cycle. Top-watering can leach the salts from the pots, but its efficiency depends on the volume of water applied. A small volume of water may simply wash the salts from the top into the bottom layer, where they are most likely to cause damage. Thus, sufficient water must be applied to leach the salts from the bottom of the pots. The objectives of this study were: 1) to quantify the short-term effects of leaching on the whole plant $\mathrm{CO}_{2}$ exchange rate of subirrigated poinsettias; and 2) to determine the effect of leaching volume on the EC of different layers of the medium.

\section{Materials and Methods}

Plant material. Poinsettia 'Freedom Red' cuttings were taken on 3 Aug. 1998 and rooted in Oasis rooting medium (Smithers-Oasis, Kent, Ohio) on a shaded mist bench. Rooted cuttings were transplanted into $15-\mathrm{cm}$ round pots filled with $1.5 \mathrm{~L}$ of a peat-lite growing medium (Metro-Mix 300; Scotts Co., Marysville, Ohio) on 31 Aug. Plants were subsequently placed on $0.9 \times 1.5 \mathrm{~m}^{2}$ ebb-andflow benches (MidWest Gromaster, St. Charles, Ill.) in a double-layer polyethylenecovered greenhouse. Plants were subirrigated daily with a nutrient solution containing a $20 \mathrm{~N}-4.3 \mathrm{P}-16.6 \mathrm{~K}$ water-soluble fertilizer (2010-20 Peat-Lite Special; Scotts Co.) containing $210 \mathrm{mg} \cdot \mathrm{L}^{-1} \mathrm{~N}\left(\mathrm{EC}=1.5 \mathrm{dS} \cdot \mathrm{m}^{-1}\right)$. This concentration was chosen, because 175 to 250 $\mathrm{mg} \cdot \mathrm{L}^{-1} \mathrm{~N}$ was used in most of the previous research with subirrigated poinsettias (Deneke et al., 1993; Dole et al., 1994; Morvant et al., 1998). The water used to mix the fertilizer solution was low in $\mathrm{Ca}^{2+}\left(10.5 \mathrm{mg} \cdot \mathrm{L}^{-1}\right)$ and $\mathrm{Mg}^{2+}\left(1.7 \mathrm{mg} \cdot \mathrm{L}^{-1}\right)$, had a low EC $\left(0.1 \mathrm{dS} \cdot \mathrm{m}^{-1}\right)$ and total alkalinity $\left(50 \mathrm{mg} \cdot \mathrm{L}^{-1} \mathrm{CaCO}_{3}\right)$, and had a $\mathrm{pH}$ of 6.4. These data indicate that the water was of excellent quality for greenhouse irrigation (Bunt, 1988).

Treatments andmeasurements. Plants were subirrigated for $30 \mathrm{~min}$ to saturate the growing medium before the start of the $\mathrm{CO}_{2}$ exchange measurements on 6 and 7 Jan. 1999. Plants were then placed in an eight-chamber, open, whole-plant photosynthesis system, designed following the principles outlined by Bugbee (1992). Ambient air was blown into acrylic chambers and air flow was measured with mass flow meters (GFM37-32, Aalborg Instruments and Controls, Monsey, N.Y.). The difference in the $\mathrm{CO}_{2}$ concentration of the air entering and exiting the chamber was measured with an infrared gas analyzer (Li-6251; LI-COR, Lincoln, Nebr.). Whole-chamber carbon exchange rate (CER; $\left.\mu \mathrm{mol} \cdot \mathrm{s}^{-1}\right)$ was calculated as the product of mass flow $\left(\mathrm{mol} \cdot \mathrm{s}^{-1}\right)$ and the difference in $\mathrm{CO}_{2}$ concentration $\left(\mu \mathrm{mol} \cdot \mathrm{mol}^{-1}\right)$. Carbon dioxide exchange rates are expressed on a per plant basis, and thus represent plant growth rate.

After $\approx 4 \mathrm{~h}$ of measurements, plants were removed from the gas exchange chambers and top-watered with $0,0.75,1.5$, or $3 \mathrm{~L}$ of water per pot, corresponding to $0,0.5,1$, and $2 \times$ the volume and $0,0.79,1.6$, and $3.2 \times$ the container capacity of the growing medium, respectively (Metro-Mix 300 has a 70\% (v/v) container capacity, the maximum amount of water the medium can hold.) Plants were then placed back in the $\mathrm{CO}_{2}$ exchange system to determine treatment effects on the $\mathrm{CO}_{2}$ exchange of the 
whole plants. Temperature in the gas exchange chambers was $21 \pm 1{ }^{\circ} \mathrm{C}$, with an 8-h dark period.

After $24 \mathrm{~h}$, the plants were removed from the gas exchange chambers. Leaf and bract area and shoot dry weight of the plants were determined. The soilless medium was cut and divided into three layers (top, middle, bottom) with baker scrapers, and $\mathrm{EC}$ and $\mathrm{pH}$ of the medium samples were determined using the saturated medium extraction method (Warncke, 1986).

The experiment was designed as a randomized complete block with four replications. Since only two replications could be measured simultaneously, the experiment was conducted on 2 consecutive days. The experimental unit was a group of two plants placed together in a gas exchange chamber and the soilless medium of these plants was combined for EC and $\mathrm{pH}$ measurements.

\section{Results and Discussion}

Medium EC of control plants (no leaching) was highest in the top layer and lowest in the bottom third of the pot (Fig. 1), which is normal for subirrigated plants (Argo and Biernbaum, 1995; Kent and Reed, 1996). The EC of the top layer $\left(7 \mathrm{dS} \cdot \mathrm{m}^{-1}\right)$ was higher than optimal, according to the guidelines of Warncke and Krauskopf (1983), but may not have had a significant effect on the plants. A visual inspection of the root systems indicated that most of the root growth occurred in the bottom part of the pots, which is normal for subirrigated plants (Argo and Biernbaum, 1995; Kent and Reed, 1996). Thus, the chemical characteristics of the top layer are unlikely to have a significant impact on growth. Argo and Biernbaum (1995) reported that the EC of the top medium layer can be as high as $36 \mathrm{dS} \cdot \mathrm{m}^{-1}$ while maintaining healthy plants. The EC in the middle and bottom layer were within the optimal range for most greenhouse crops (2$3.5 \mathrm{dS} \cdot \mathrm{m}^{-1}$ ) (Warncke and Krauskopf, 1983), suggesting that the plants were not exposed to osmotic stress during the growing season.

Top-watering the pots after production significantly decreased the EC of the top and middle layers of the growing medium (Fig.1). However, watering the plants with a relatively small volume $(0.75-1.5 \mathrm{~L})$, increased the EC of the bottom layer of the growing medium from 2.1 to $2.6 \mathrm{dS} \cdot \mathrm{m}^{-1}$, indicating that salts were washed from the top part of the pot into the bottom layer. Applying a larger volume of water $(3 \mathrm{~L})$ decreased the $\mathrm{EC}$ in the bottom layer of the medium by $\approx 0.4 \mathrm{dS} \cdot \mathrm{m}^{-1}$, indicating that the volume applied in top-watering must be larger than the volume of the growing medium to reduce the $\mathrm{EC}$ of the bottom layer.

Photosynthesis normally is very sensitive to salt stress (Reddy et al., 1997), but the leaching treatments had no significant effect on photosynthesis, either expressed per whole plant or per unit leaf area (results not shown). Although previous reports on the effects of salt stress on photosynthesis have been inconsistent, photosynthesis is reduced in most species when salt levels in the growing medium

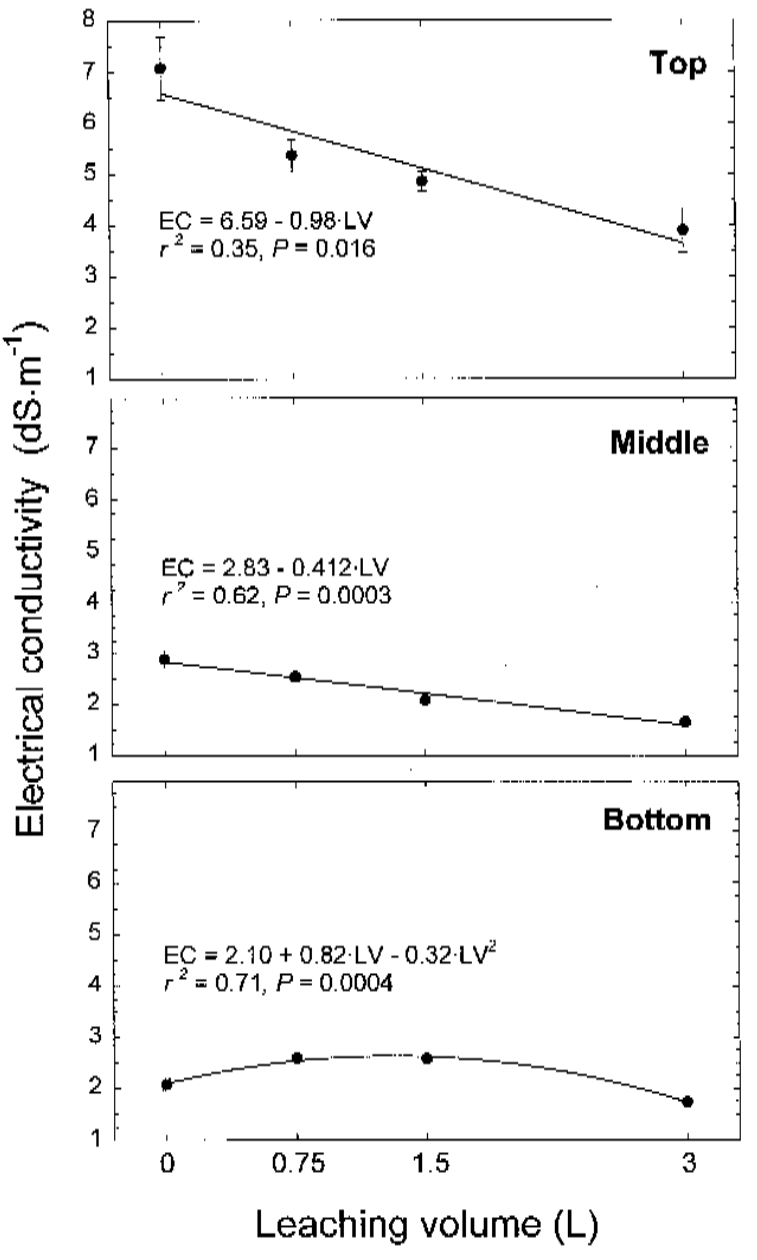

Fig. 1. The effect of postproduction leaching $(0,0.75,1.5$, or $3 \mathrm{~L} /$ pot $)$ on the electrical conductivity of the growing medium of subirrigated poinsettias. The electrical conductivity of three layers of medium (top, middle, and bottom) was determined using the saturated medium extraction method. Data points are the average of four replications and error bars represent the standard error of the mean. Lines indicate significant linear or quadratic effects of the leaching volume (LV) on electrical conductivity $(P \leq 0.05)$.

are superoptimal (Heuer, 1996). For example, leaf photosynthesis of passionfruit (Passiflora edulis Sims) is highest with a nutrient solution $\mathrm{EC}$ of $6.8 \mathrm{dS} \cdot \mathrm{m}^{-1}$, but decreases rapidly when the EC is higher than optimal (Letchamo et al, 1993). Short-term effects of salinity on carbon assimilation are normally caused by the decrease in osmotic potential of the growing medium (Plaut, 1995). Watering the poinsettia plants with 0.75 or $1.5 \mathrm{~L}$ resulted in only a 0.5 $\mathrm{dS} \cdot \mathrm{m}^{-1}$ increase in the EC of the bottom layer of the medium. Apparently, this increase did not cause an osmotic effect large enough to affect photosynthesis. This is not surprising, since the EC remained within the recommended range of 2 to $3.5 \mathrm{dS} \cdot \mathrm{m}^{-1}$ (Warncke and Krauskopf, 1983). The $\mathrm{pH}$ of the growing medium decreased from the top to the bottom of the pots, but was not significantly affected by the watering treatments (data not shown).

Surprisingly, the leaching treatments affected the dark respiration rate of the plants significantly. Leaching the plants with 0.75 or 1.5 $\mathrm{L}$ reduced the respiration rate of the plants by $20 \%$ (Fig. 2). The reason for this reduction in respiration is not clear. Literature reports on the effect of salinity on respiration are inconsistent. Rains (1972) stated that increased sa- linity generally increases the respiration rate of plants, but a variety of other reports indicate that $\mathrm{NaCl}$ stress reduces (Lapina and Popov, 1970) or has no effect on respiration (Fernandez-Pascual et al., 1996; Marler and Zozor; 1996; Mickelbart and Marler, 1996). On the other hand, aboveground respiration of smooth cordgrass (Spartina alterniflora Loisel.) increases in response to increasing salinity (Hwang and Morris, 1994). A complicating factor in the comparison of previous research with the data from this study is that most published reports concern the effects of $\mathrm{NaCl}$ on plants. The effect of $\mathrm{NaCl}$ on respiration differs from osmotic shock caused by sorbitol (Petruzzelli et al., 1992) and may be ion-specific. I did not quantify the mineral composition of the salts in the different levels of the growing medium, but high levels of $\mathrm{Na}^{+}$ or $\mathrm{Cl}^{-}$are unlikely and the effects of salinity on respiration may thus be different from $\mathrm{NaCl}$ stress.

Regression of dark respiration rates on the EC of the different medium layers confirms that the EC of the bottom layer affected plants more than the EC of the middle and top layers. There was a highly significant $(P=0.007)$, linear decrease in dark respiration with in- 
creasing EC of the bottom section of the growing medium, although the EC of the top and middle layers were not correlated with the respiration rate (Fig. 3).

The extent of salt buildup in the top layer of the growing medium depends on the environmental conditions and concentration of the fertilizer solution. When evaporative demand is higher or more concentrated fertilizer solutions are used, the EC in the top layer of the growing medium could become even higher than in this experiment. Following top-watering, this would probably result in higher EC levels in the medium and bottom layers of the pots, thus increasing the possibility of osmotic stress. However, the results of this study indicate that top-watering of subirrigated plants causes only a relatively small increase in the $\mathrm{EC}$ of the bottom layer of the growing medium, where the EC is unlikely to become higher than optimal $\left(>3.5 \mathrm{dS} \cdot \mathrm{m}^{-1}\right)$ unless that of the top layer is well above $7 \mathrm{dS} \cdot \mathrm{m}^{-1}$.

Only short-term effects of postproduction leaching on the growing medium and physiology of the plants were studied. However, given the small increase in the EC of the bottom layer in the 0.75 and $1.5 \mathrm{~L}$ treatments, these leaching treatments are unlikely to have any detrimental long-term effects during the postproduction period. During subsequent waterings, more salts would be leached out of the pots, thus further limiting the potential for EC-related problems.

\section{Conclusions}

Postproduction top-watering of subirrigated poinsettias leached accumulated salts from the top layer to the middle and bottom layers of the growing medium. Watering with 0.75 or $1.5 \mathrm{~L}$ ( 0.5 or $1 \times$ the volume of the growing medium) increased the EC of the bottom layer of the growing medium by $0.5 \mathrm{dS} \cdot \mathrm{m}^{-1}$ and decreased the dark respiration rate of the plants. The increase in EC of the bottom layer had no

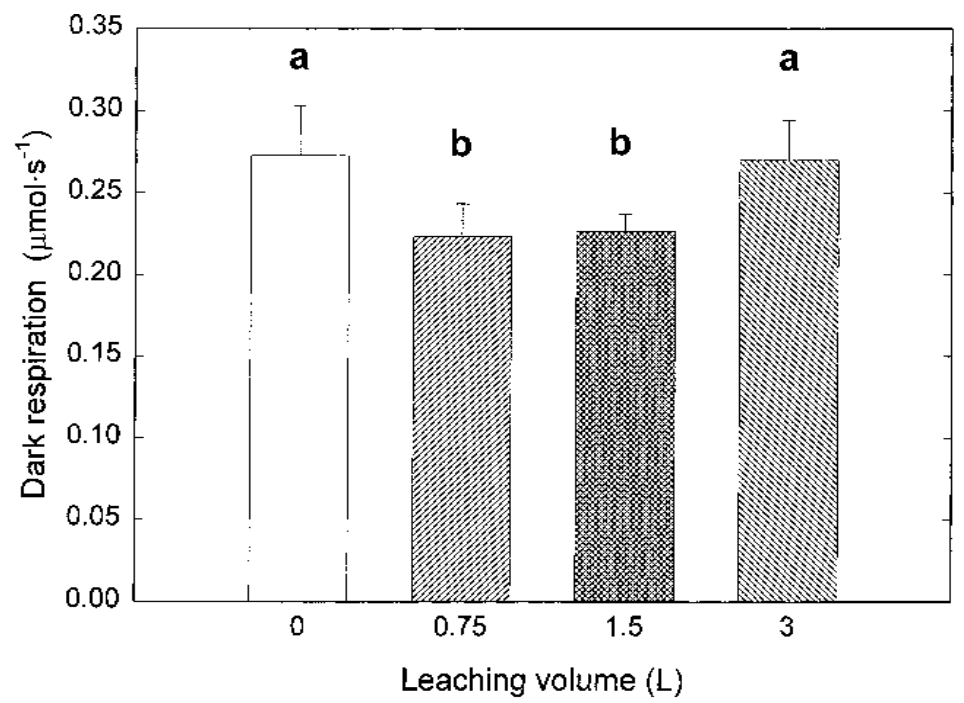

Fig. 2. The effect of leaching volume $(0,0.75,1.5$ or $3 \mathrm{~L} /$ pot $)$ on the respiration of subirrigated poinsettias during the dark period following leaching treatments. Data represent the whole-plant respiration (including the root zone), expressed on a whole-plant basis and are the average of four replications. Error bars represent the standard error. Mean separation by Fisher's protected least significant difference $(P$ $\leq 0.05)$.

detrimental short-term effects on the plants. Watering the plants with $3 \mathrm{~L}(2 \times$ the medium volume) resulted in a decrease in the EC of all layers of the growing medium. Leaching salt from subirrigated poinsettias does not appear to be necessary to maintain plant quality and is not recommended.

\section{Literature Cited}

Argo, W.A. and J.A. Biernbaum. 1994. Irrigation requirements, root-medium $\mathrm{pH}$ and nutrient concentrations of Easter lilies grown in five peatbased media with and without an evaporative barrier. J. Amer. Soc. Hort. Sci. 119:11511156.

Argo, W.A. and J.A. Biernbaum. 1995. The effect of irrigation method, water-soluble fertilization, preplant nutrient charge, and surface evapora- tion on early vegetative and root growth of poinsettia. J. Amer. Soc. Hort. Sci. 120:163169.

Bugbee, B. 1992. Steady-state canopy gas exchange: system design and operation. HortScience 27:770-776.

Bunt, A.C. 1988. Media and mixes for containergrown plants. 2nd ed. Unwin Hyman, Boston.

Deneke, C.F., B.K. Behe, and J.W. Olive. 1993. Influence of subirrigation on postproduction longevity of poinsettias, p. 4. In: Research report 1993. Ornamentals. Res. Rpt. Ser. 8. Alabama Agr. Expt. Sta. Auburn.

Dole, J.M., J.C. Cole, and S.L. von Broembsen. 1994. Growth of poinsettias, nutrient leaching, and water-use efficiency respond to irrigation methods. HortScience 29:858-864.

Dubey, R.S. 1996. Photosynthesis in plants under stressful conditions, p. 859-875. In: M. Pessarakli. Handbook of photosynthesis. Marcel

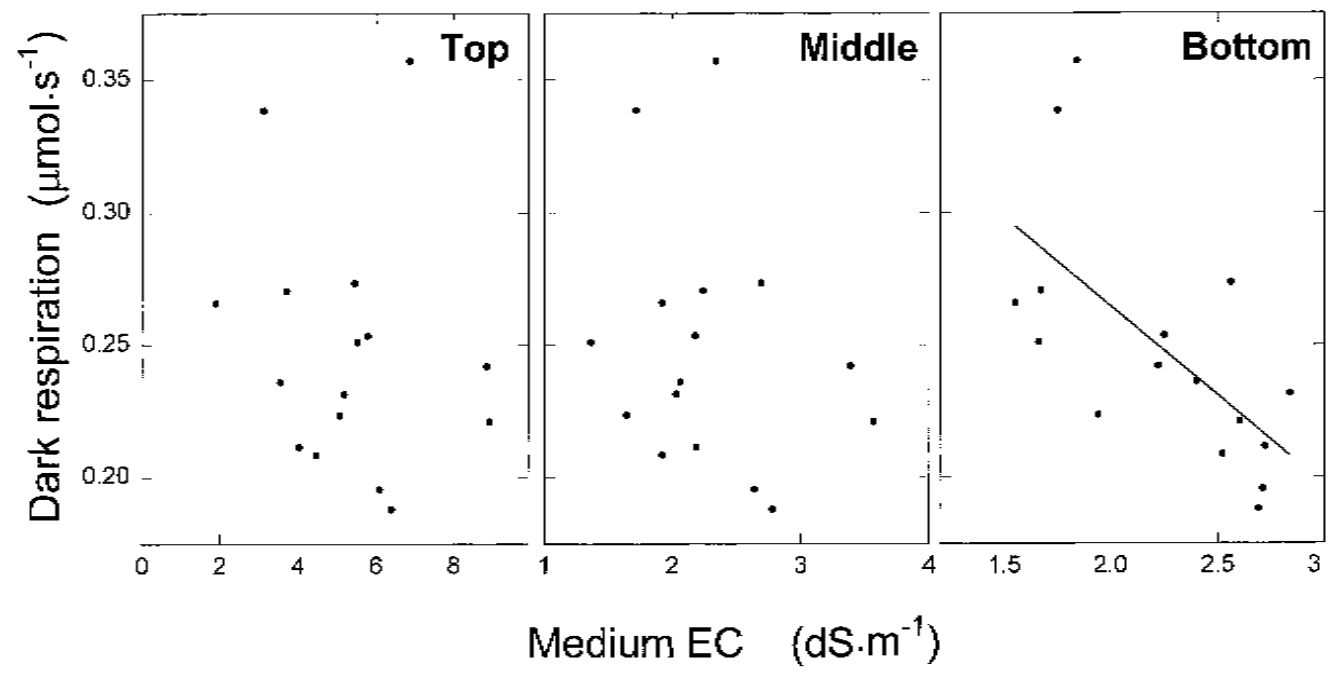

Fig. 3. The correlation between the electrical conductivity (EC) of the top, middle, and bottom layers of medium and the respiration of subirrigated poinsettias. Respiration rates of the plants were measured during the dark period following the leaching treatments and are expressed on a per plant basis. Only the EC of the bottom layer of the growing medium had a significant effect on the respiration rate of the plants $\left(\mathrm{R}_{\text {dark }}=0.4-0.068 \cdot E C ; r^{2}=0.42, P=0.007\right)$. Data points for every experimental unit are shown. Note the different scales on the $\mathrm{X}$-axes. 
Dekker, New York.

Fernandez-Pascual, M., C. de Lorenzo, M.R. de Felipe, S. Rajalakshmi, A.J. Gordon, B.J. Thomas, and F.R. Minchin. 1996. Possible reasons for relative salt stress tolerance in nodules of white lupincv. Multolupa. J.Expt. Bot. 47:17091716.

Heuer, B. 1996. Photosynthetic carbon metabolism of crops under salt stress, p. 887-896. In: M. Pessarakli. Handbook of photosynthesis. Marcel Dekker, New York.

Hwang, Y.H. and J.T. Morris. 1994. Whole-plant gas exchange responses of Spartina alterniflora (Poaceae) to a range of constant and transient salinities. Amer. J. Bot. 81:659-665.

Kent, M.W. and D.W. Reed. 1996. Nitrogen nutrition of New Guinea impatiens 'Barbados' and Spathiphyllum 'Petite' in a subirrigation system. J. Amer. Soc. Hort. Sci. 121:816-819.

Lapina, L.P. and B.A. Popov. 1970. Effect of sodium chloride on the photosynthetic apparatus of tomatoes. Soviet Plant Physiol. 17:477-481.

Letchamo, W., H.L. Xu, B. Desroches, and A. Gosselin. 1993. Effect of nutrient solution concentration on photosynthesis, growth, and content of the active substances of passionfruit. J. Plant Nutr. 16:2521-2537.

Marler, T.E. and Y.Zozor. 1996. Salinity influences photosynthetic characteristics, water relations, and foliar mineral composition of Annona squamosa L. J. Amer. Soc. Hort. Sci. 121:243-248.

Mickelbart, M.V. and T.E. Marler. 1996. Root-zone sodium chloride influences photosynthesis, water relations, and mineral content of sapodilla foliage. HortScience 31:230-233.

Morvant, J.K., J.M. Dole, and J.C. Cole. 1998. Irrigation frequency and system affect poinsettia growth, water use, and runoff. HortScience 33:42-46.

Plaut, Z. 1995. Photosynthesis in plant/crops under water and salt stress, p. 587-603. In: M Pessarakli. Handbook of plant and crop physiol- ogy. Marcel Dekker, New York.

Petruzzelli, L., M.T. Melillo, T.B. Zacheo, and G. Taranto. 1992. Physiological and ultrastructural changes in isolated wheat embryos during salt and osmotic shock. Ann. Bot. 69:25-31.

Rains, D.W. 1972. Salt transport by plants in relation to salinity. Annu. Rev. Plant Physiol. 23:367388.

Reddy, M.P., U.S. Rao, and E.R.R. Iyengar. 1997. Carbon metabolism in plants under stress, $p$. 159-190. In: P.K. Jaiwal, R.P. Singh, and A. Gulati (eds.). Strategies for improving salt tolerance in higher plants. Science Publ., Enfield, N.H.

Warncke, D.D. 1986. Analyzing greenhouse growth media by the saturation extraction method. HortScience 21:223-225.

Warncke, D.D. and D.M. Krauskopf. 1983. Greenhouse growth media: Testing and nutrition guidelines. Michigan State Univ. Coop. Ext. Serv. Bul. E. 